\title{
Practical Techniques for Restoration of Architectural Formation Elements in Historical Buildings
}

\author{
Mahran Anwar \\ Conservation Department, Institute of Tourism, Hotel Management and Restoration, Alexandria, Egypt \\ Email: mahranrestorer@gmail.com
}

How to cite this paper: Anwar, M. (2019) Practical Techniques for Restoration of Architectural Formation Elements in Historical Buildings. World Journal of Engineering and Technology, 7, 193-207. https://doi.org/10.4236/wjet.2019.71013

Received: December 24, 2018

Accepted: February 11, 2019

Published: February 14, 2019

Copyright $\odot 2019$ by author(s) and Scientific Research Publishing Inc. This work is licensed under the Creative Commons Attribution International License (CC BY 4.0).

http://creativecommons.org/licenses/by/4.0/

\begin{abstract}
Restoration of architectural formation elements is basically trying in estimating the optimization method which places it old architectural artist in his work. The article aims at rooting the methodology of restoration of the architectural formation elements. It is essentially intellectual effort by the restorer in assessing the best way the artist and the old architect in his work. In order to reach the purpose behind this works and analyze the original available techniques in the creation period, the restoration process can be completed as fully as possible. The research is concerned with re-confidence in the classical methods in the restoration of buildings as consolidation and reconstruction. The classical method is a real way to restore the building to its original form especially in the availability of all technological tools to achieve reporting and documentation. It is not necessary to extension in using unapplied materials and technique. In this regard, the research was able to provide solutions, ideas and techniques that helped preserve and restore elements of architectural formation. The research also pointed to the importance of linking the physical and plastic aspects of the archaeological element.
\end{abstract}

\section{Keywords}

Formation, Architectural Elements, Casting, Stitching, Reconstruction

\section{Introduction}

Formation included any process whose performance depends on a set of elements in a specific organizational relationship to control the composition of these elements. The variation of form existed to distinguish the formation product. Therefore the human mind can be associated this form with unique quali- 
ties. Is it process that regulated the relationships between the elements, vocabulary and means of formation in order to achieve the beauty and harmony? It is concerned with perfect relationships and compatibility between elements. The restoration of architectural elements is basically attempt and mentality dialogue in choosing the best way that the historical architect. Artist and builder are followed to create and construct this mixture of architecture elements as an example; the color, the shape, the formation of the unit. The purpose of the dialogue is to reach to the old picture of the original element. In addition, dissection and analysis in the historical building structure are to recognize all the structure and architecture features, and the role of each feature in the building life, structure, architecture and artistic value. In this field there are many applications carried out by specialists; Alalfy [1] presented the development of procedures for the restoration of buildings according to the state of damage and deterioration through the following classification; Quick process includes the work of steel and reinforcement is temporary to prevent collapse, and urgent process to stop the deterioration such as cracks in the walls or the dismantling of the ceilings. periodic maintenance and cleaning, and repairs. The work of monitoring is before and after the implementation of rehabilitation and rehabilitation projects. In 1936, Giovann [2] had identified four types of restoration; restoration by consolidation, restoration by decomposition "anastylesis", restoration by liberation, restoration by completion or renovation. Sherif, Murad and Ashraf [3] applied the technique of mathematical modeling to the study of the structural stability of the archaeological buildings under the influence of different loads, both vertical and horizontal, and they created two models of the minjuk al-Yusufi as a Mamluk model and the minaret of al-Husayni as a model of the Ottoman minaret. Croci [4] also has the idea of packing the serious cracks in the minaret with Tie bars or cables made of stainless steel, which has the suitable flexibility, during the restoration of Hassan Pasha Taher's minaret. Mahran [5] presented a completely application model for the works of disassembly, reconstruction including unique formation elements. Abdel Tawab and Mahran [6] also presented their applied experiments in cleaning the formation elements of the stone facades of the Sabil Shaheen Agha and the restoration of the Mural stucco at the Ulmass El Hajib [7] mausoleum in Cairo.

\subsection{Architectural Formation \& Sculpture}

Structural provisions or training engineering to form represents an abstract level to build the physical image of article scrapes phenomenon to reflect the integration of a set of plastic between the components and elements of the laws. The characterization of the degree of harmony and complementarity and integration between the structural relations governing the structure of the product specified in formulating specific production conditions, this type of aesthetics deals with shapes and formations as a goal in it, beside to attention to the function and its content. A detective aesthetics required which we can define this in utility, dura- 
bility and beauty, classified beauty requirements in six basic criteria: ordering, disposition, rhythm, symmetry, Proportion, ratios, decoration, and distribution.

\subsection{Sculpture and Formation Relation to Architecture}

- Autonomous formation.

- Functional formation.

- Architectural formation produces other architectural composition.

- Architectural formation produces mural painting.

- Operations on simple shapes to be final output a composite form addition, removal, cutting, tracking and repetition.

\subsection{Restorer Tools for Restoration Formed Elements (Figure 1)}

- Read the item.

- Cluster analysis of sculpture.

- Follow the formative lines and its duplicates.

- Shop drawing in suitable scale.

- Installation of formative pieces.

\section{Practical Techniques in the Restoration of Architectural Formation Elements}

\subsection{Restoration by Architectural Simulation and Reforming of Structural Elements}

The simulation work must be realized for the congruence relationship of the archaeological building relating to the sculpture, construction and composition by physical simulation using the same methods of construction, materials and following the same pattern in forming process. The renovation of the building is done in a different way. The most important of which is the extension of the building with the same type, materials and methods of construction and using the same details. These works are carried out through the availability of building materials and the possibility of construction in the same original ways, especially if the building is an important building visually or important in the composition of the general character of the city.

Re-construction of the architectural elements formed from a group of separated blocks, which through the relations of neighboring and convergence construct

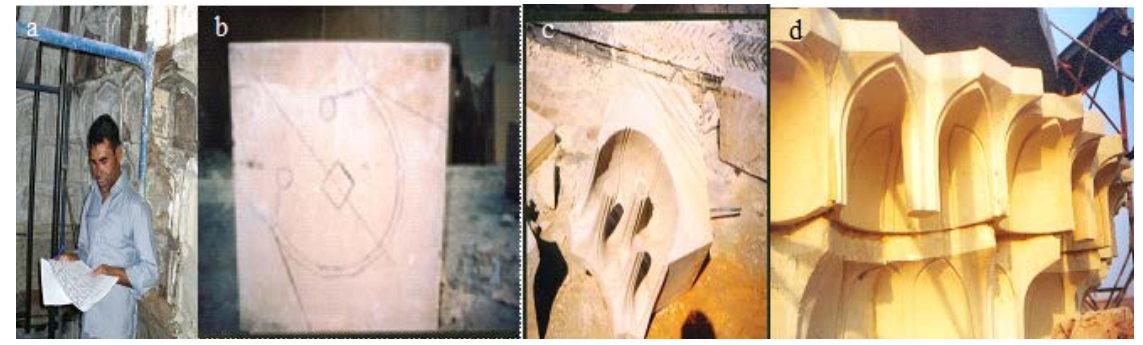

Figure 1. Restorer's tools for restoration formed elements; (a) read and understand, (b) drawings, (c) the process of sculpture and finishing, (d) construction. 
elements with a dimension. Therefore, the work is still closer to what we call structural sculpture which requires precision and professionalism in the industry where these delicate works need to work more accurate restoration works such as the re-sculpting stalactites architectural element located in the transition areas of the dome from the inside as well as leading the entrances of buildings. The reconstruction of Al-Bayt (Muhammad is the Messenger of Allah peace be upon him) mosques in Cairo is one of the most important examples of this Figure 2.

\section{- The Zinbee Mosque}

The mosque is located in the square of Sayeda Zeinab in the district named after its name and the mosque has three expansions.

- The first expansion was carried out in the forties of the twentieth century on the same architectural style.

- The second expansion took place in the sixties of the twentieth century and was characterized by the addition of three entrances on Al Sadd Street.

- The third expansion took place at the end of the $20^{\text {th }}$ century and the beginning of the new millennium. The expansion included the northern part of the original mosque overlooking the Al Sadd Street and the original mosque, which is the expansion that will identify the most important architectural and formation features.

\subsection{Restoration by Stitching}

Damage and collapse have when all structural element acting independently then the aim of stitching is returned to the building a minimum of structural continuity and we can be considered location and direction of cracks directory path fastening, according to the specifications of the building [8].

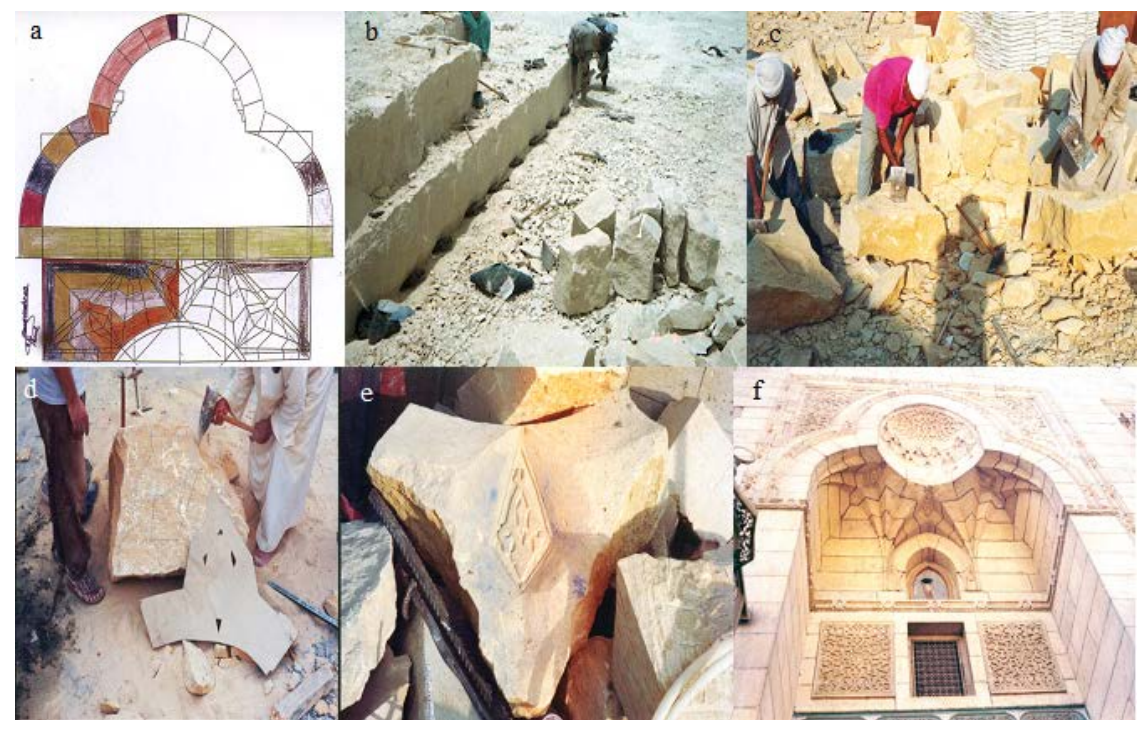

Figure 2. Evolution of the formation journey from the beginning of (a) the drawing \& design; (b) the process of quarrying; (c) the process of refinement and primary sculpture; (d) the process of sculpting and removing the outside the design lines; (e) the process of finishing sculpture; (f) construction process and access to the simulated model of the original formation. 


\subsubsection{Mechanical Stitching}

Stitching and rebounding of cracks and flacking by mechanical methods using steel beams treatment by anti-corrosion according to structural calculations. As for the restoration of deformation in arches, it is often seen in stones or keystones, without determine the cause and treatment source of collapse or ensure no continuity and not repeat it again. The treatment doesn't useful, because the problem is constant, whether collapse in foundations or increase in weight. The process starts with secure the landing area with the work of the wooden and iron wrenches. Second push the stones in a direction perpendicular to the arch by the oil compressor to return the stone to its original position, also can using the hand lift to press the piece of stone and return to its original position. Third transplanting collection of wood beams in the cracks gap to make pressure and fill the gap between the two sides of the neighboring stones. Fourth using fillers lime and sand with adding $10 \%$ white cement, finally finishing and repointing, as shown in Figure 3.

\subsubsection{Chemical Stitching}

The adhesion is done using some chemical adhesives, which are homogeneous with the properties of the original building materials. Repairs should start from the lower levels according to the following steps:

- Open the cracks with diamond disks from both sides and clean the cracks with compressed air to remove all dust.

- Closing the remaining part of the crack with the same repair material but with a bigger percentage of bonding material to keep the injected material inside.

- Inject the repair materials with sufficient pressure to fill all the crack width along the thickness of the walls to assure full penetration [9].

- Materials used in the repair in each location must be include the same type of stones or bricks and the same chemical composition but will be mixed together with a suitable bonding agent Sika latex or add bond in order to bond more with the original material surrounding it.

\subsection{Restoration by Injection}

Injection of the internal filler under pressure to strengthen the walls, the process

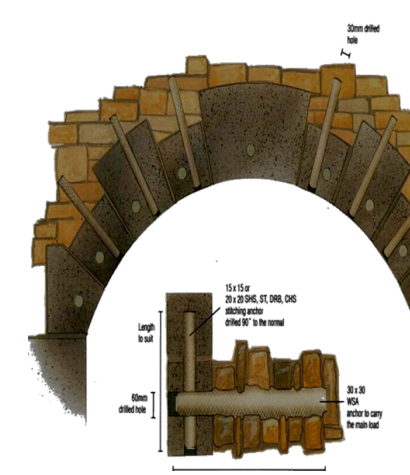

(a)

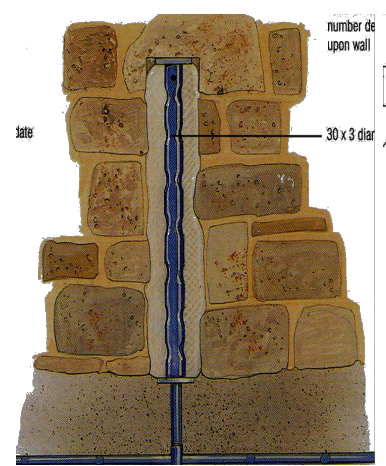

(b)

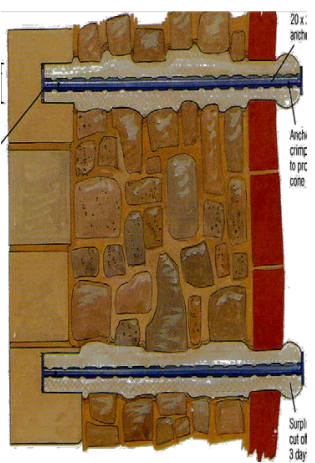

(c)

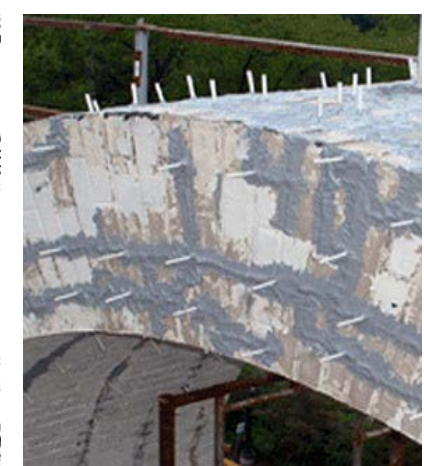

(d)

Figure 3. Different horizontal and vertical mechanical types of anchors employ wedging action to provide anchorage. 
of adding a bonding in the form of liquid to the construction, as the walls of the buildings are dependent on their consistency and balance by filling, especially in the double skin construction with core filling. Therefore, the aim of the injection is to fill the gaps within the walls resulting from the degradation of the old mortar and work to re connect between the wall and internal filling and give it the durability required. The method of injection under pressure, which uses either manual or mechanical pumps, which usually consists of a mixer to mix the mortar and pump and pull and delivery slots to connect the mortar to the openings of the walls, and this is the most used method of strengthening the walls of buildings because of its advantages. Thermal and adhesion tests should be performed on the injection material to prove compatibility with the surrounding materials before being used (Figure 4).

\subsection{Restoration by Reconstruction}

It is in terms of architecture and structure, all the work directed to the destroyed and collapsed, whether it is just a break-up, fragmentation, partial demolition or even total destruction, with a purpose to reconstructing the structural and architectural configuration of the archaeological building.

The domes have a large lateral propulsion force at the center point, moved to the walls on which these domes based by their own weight. The domes are usually composed of a compact stone structure. These stone blocks form one integral element. Because the stone has high resistance to the pressure forces, in the reconstruction process, any potential tension or stresses on the various dome sections of the dome must be avoided. Therefore, it is necessary to pay attention to the reinforcement and tethering of the dome to resist horizontal forces (Figure 5).

\subsection{Restoration by Disassembly \& Reassembly}

Reconstructing and assembling the architectural formation elements, since the original elements are present, although they are scattered, using the elements of the old building without any additions in the process of re-assembling and assembling all the pieces that can be it stabilizes in place.
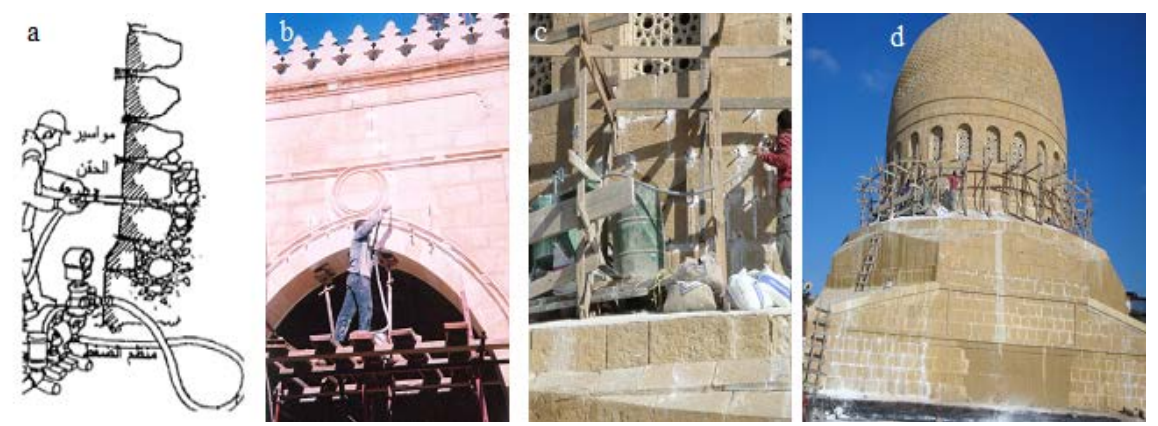

Figure 4. Various applications for injection work in reinforcing the internal fillings and filling gaps in the archaeological buildings (a) Sketch showing injection technique (b) Injection in the arches of the mosque Sayda Soukayna (c, d) Injection for re bonding of Internal filling dome of Ebrahim El Dousouky. 


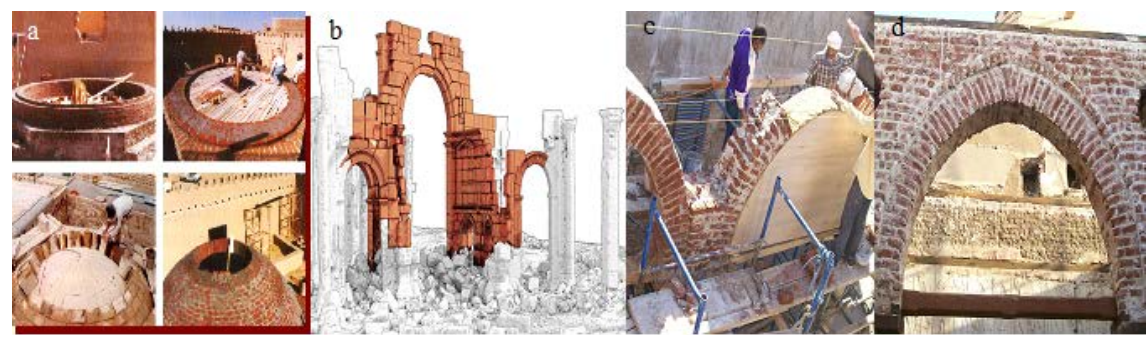

Figure 5. Various multiple methods for reconstruction of curved line structure as Arches and Domes (a) reconstruction stones and brick domes in Riad El Khoubra in KSA (b) Imagine how to reconstruction the destroyed part of the arch of Tadmor in Syria (c, d) reconstruction of brick arches in Abu Hagag Mosque in Luxor.

Arches are the bearing elements that distributed the loads from the ceiling to columns and side-bearing walls until it reached to the bearing soil. This process depended on the arches geometry and shape to resist the pressure and stress (Figure 6).

\subsection{Restoration by Reinforcement with Back Support Holder}

Technology is achieved by the access to the backgrounds of mural painting and reinforced by the application of back rest holder of polyester (GRP). The aim of this stage is to reinforcement the background of the decoration and also re-bonding gypsum formation elements. The technique has been applied to reinforce decorative ceiling of Sursoq Palace in Alexandria through the implementation of the following stages as shown in Figure 7. Referring to the anatomical structure of these decorative ceilings consisting of:

- iron beams, the main support of these ceilings;

- Holder from cross thin wood;

- Layers of oil paints on Jesso Grounds.

In general, the factors of damage as well as the aging of these components were the attacks of insect and microorganisms which caused various decay of thin cross wood. In addition to the construction movement of all elements of the palace, therefore, there is a need to repond a process of linking of all the elements of the formation of the Jesso formation with each other and transfer the loading places from the points of the old pillars to the points of direct focus with the new beams used to reinforcement the ceilings of the palace recently. This stage aims to reinforcement the background of the decoration and the elements of the Jesso formation.

- A thin layer of polyester was made without reinforcing with thickness $2 \mathrm{~cm}$.

- Another layer of polystyrene Reinforcement with fiberglass of $1 \mathrm{~cm}$.

- Galvanized tees iron bars of $8 \mathrm{~mm}$ diameter are placed in the middle of area.

- Final layer of the support is then followed by the use of polyester. The end thickness of the holder is $5 \mathrm{~cm}$, reinforced with fiberglass, from which the load points are transferred and the loads are distributed to the new steel beams which will be used recently in the reinforcement. 

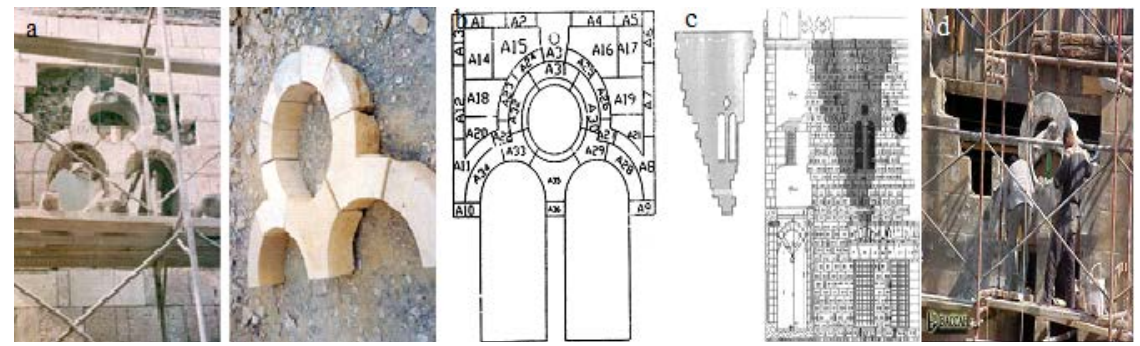

Figure 6. Various multiple methods for Disassembly \& Reassembly some of architectural formation elements $(a, b, c)$ Numbering, dismantling and re-assembling of a composite arch in Hassan Basha Taher Mosque (d, e) Numbering, dismantling and re-assembling of a composite arch in Ashraf Qaitbay Mosque.
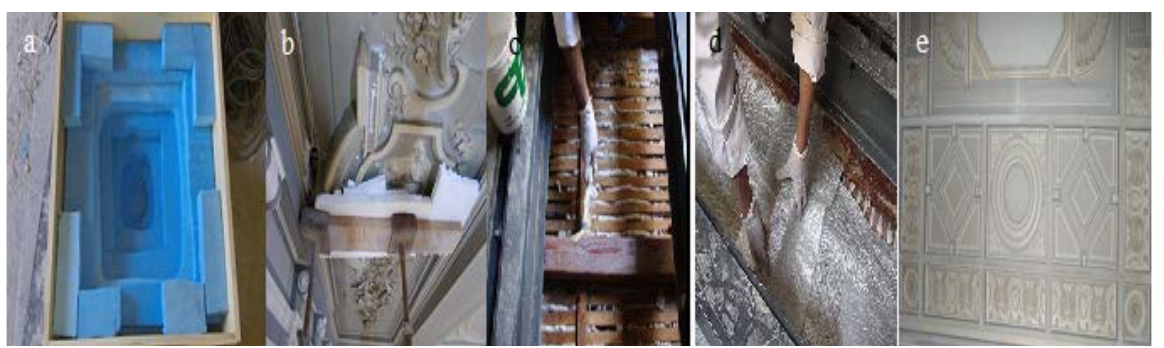

Figure 7. Stages of re construction of the back-support holder from GRP, (a, b) front protection work (c, d) implementation back support holder from GRP (e) decorative ceiling after reinforcement and removal protective layers.

\subsection{Restoration by Rebalancing Tendencies}

Most vertical elements facing danger of tendencies, especially when they suffer from lateral load pressures such as earthquakes and vibrations. Especially columns are the bearing elements in the various archaeological buildings, on which the ceilings and arches based in. When reconstructing, the balance of these columns must be adjusted based on special instruments as the level instrument, total station, and theodolite. The axis of the pressure forces as the central pressure forces are the main loads applied to these columns, to make sure that stresses are within the allowed values. It is also possible to take advantage of the process of reconstructing and balance columns to adjust or change the wooden pillow, which are usually a middle stage between the arches bottom and the capital of the column, for the importance of its structural role in the reduction of loads and absorption of vibrations (Figure 8).

\subsection{Restoration by Stabilize Tendencies}

In some cases, it is not possible dismantling buildings that suffer from tendencies, especially in the case of brick minarets, therefore, the current case (Esna Minaret) which is a consider composite formation element. The restoration plan is constructed following primary procedures; Monitoring in all directions at different heights, monitoring its stability, determining the seriousness of the tendencies based on the value of the tendencies for the height and thickness of the wall and the movement and stability of this tendency [10]. 


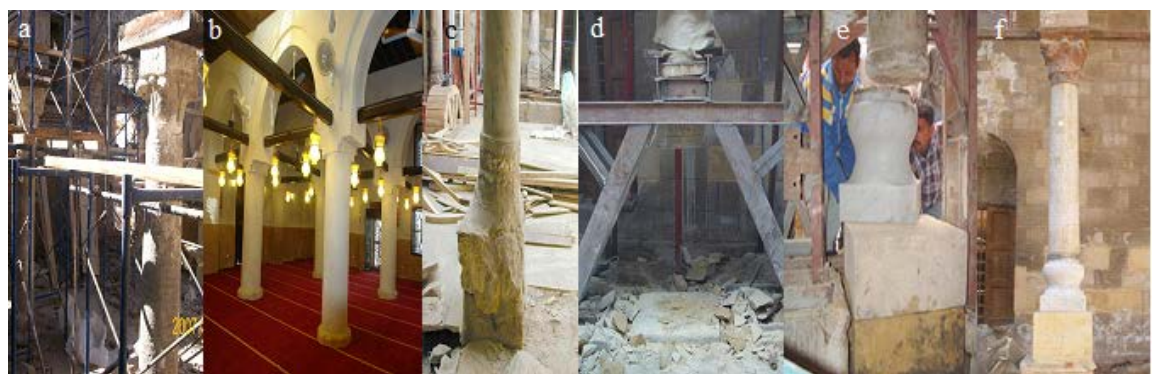

Figure 8. Different applications to restore balance and vertical columns on different types $(a, b)$ re-balancing and vertical columns of bricks for the Abu Hajaj Mosque (c, d, e, f). rebalancing the tendencies of one of the marble columns of the Mosque of Ibn Yarbak.

The minaret of the ancient mosque in Esna in Upper Egypt is one of the most important and oldest minarets that still remain and retain its original architectural features so far, which makes it a very important attempt to keep this minaret in the memory of human architecture. The minaret was built in the early Fatimid period by Saad al-Sartakin al-Juyoshi in the reign of al-Mustansir in Fatimid at $474 \mathrm{AH} \& 1802$ A.C. It find near the temple of Esna. The minaret was built with a system of bearing walls structure and wooden beams. The minaret is about 25 meters height. There were many reasons for the damage minaret, such as the soil under the minaret, as well as the high level of ground water under the foundations, in addition to the horizontal loads that were exposed to the minaret in the impact of earthquakes, especially the earthquake of October 1992, as well as the location of the minaret in center town of public area. The studies for diagnostic of the current situation were prepared before starting of restoration project to determine the practical method for the reinforcement and restoration, which included the structural and architectural restoration works.

\section{Mechanical damage of minaret with the impact of horizontal loads}

When the walls are faced horizontal loads, it has a sideways displacement, and this displacement is the result of curvature and cutting, behavior of the walls under the load of horizontal pressure has three different main types:

- Flexural mode: is the most important manifestation is the presence of horizontal cracks in the tensile area, and these cracks is a separation between the mortar and brick as a result of vertical stress on the horizontal mortar, and the presence of brick fractures in the pressure zone due to increased pressure, and also when the wall resistance of the shearing is high [11].

- Shear mode: this behavior is generated when the height of the wall is equal to or less than its width and resistance to the wall for cutting is weak; this results in axial and horizontal cracks.

- Flexural \& Shear mode: this type of behavior is generated when the height of the wall is equal to its width, and when the wall resistance for cutting and bending is equal.

\section{Causes of deviation and tendencies in minaret}

- A flow of soil as a result of insufficient hardness in soil.

- A reduction in pore and grain volume, resulting in creep and reduction in 
the structural.

- A progressive seasonal rotation of tall structures due to fluctuating ground-water level.

- Wetting and softening of soil from water more than its natural condition can pose dangers for foundations that can happen in several ways:

o Heavy surface rain, underground flow of water when reach soft clay soils; they retain it and become very soft. Soft soil does not bear loads well, causing heavy loads as minaret loads to landing in soil, tendencies and positional crushing of foundations.

o Due to poor drainage; if water is allowed to "pool" next to minaret due to poor soil level, clogged gutters or some other factor, soft clay soils around the foundation will absorb the water, they will soften more. This can cause to deformation of the foundation.

o Plumbing leaks and broken water lines can saturate soils around it, potentially weakening their load-bearing capacity and creating a void below foundation.

\section{Plan of restoration of the minaret (Figure 9)}

- Structural consolidation of minaret foundations by injection and micro piles.

- Completion of missed parts and replacement of damaged elements and materials of the composition of the minaret of brick and wood.

- Reinforcing the internal staircase.

- Stitching and reinforcement by the wooden beams.

- Dismantle and removal of metal constructions.

- Test and ensure the stability of the minaret and stop the tendencies on the current inclination without increasing.

- Restoration and reinforcement of the wooden formation of the upper balcony.

- Remodeling the original shape of the openings.

- Restoration of the decoration elements on the exterior minaret.

\subsection{Restoration by Completion}

The completion of archaeological buildings in its missing parts is one of the most important processes in the field of restoration [12]. It is one of the tools of reconstruction therefore return all element details means to have a clear picture of its original state by the respect the original components and materials, because of the achievements of these operations to obtain the continuity of archaeological building, with its construction, architectural and decorative details (Figure 10).

\subsection{Restoration by Replacement}

The restoration work directed at the elements that still exist but have completely lost their ability and their principal functions. It became broken letters in the construction system of the building, which must be corrected and evaluated for 


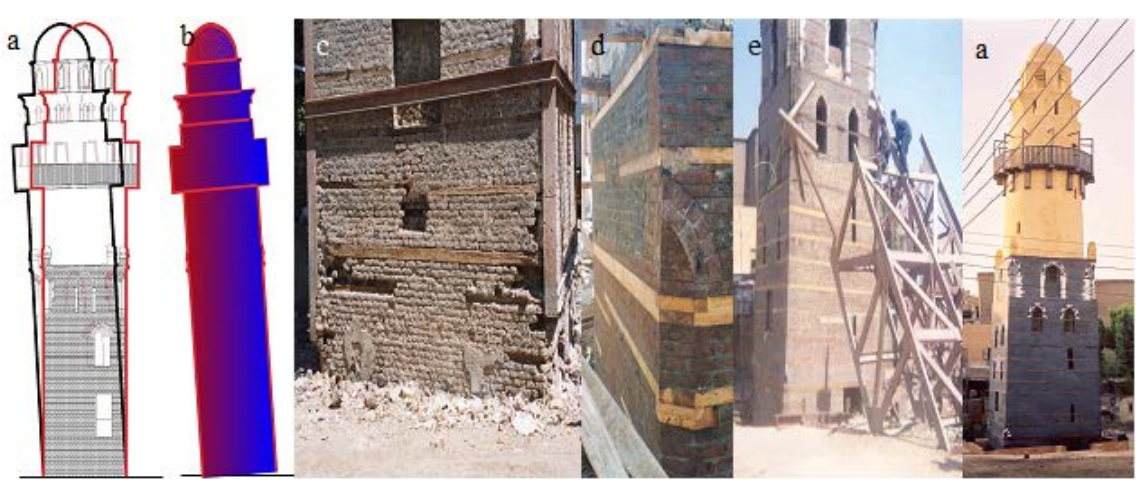

Figure 9. Stabilization the tendencies of the Esna minaret $(a, b)$ architectural documentation (c) the base of the minaret after its tendencies and suffered many problems of damage (d) consolidation of the minaret from the outside by replacement of damaged elements, completion of missed parts and re stitching by wooden beams (e) removal of the steel works after completion of the repair work (f) minaret after restoration and stabilization of tendencies.

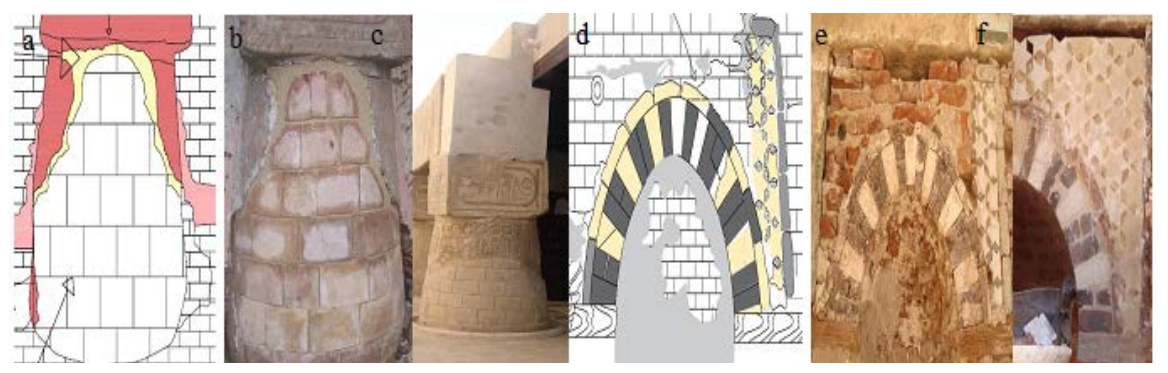

Figure 10. Multiple and variety methods for completion (a, b, c) completion of missing parts from sand stone in one of the columns of the Luxor Temple (d, e, f) completion of the missing composition elements of bricks, stone and wood in the mihrab of $\mathrm{Abu} \mathrm{Al}$ Hagag mosque.

the rehabilitation of the structural safety of the building. This damaged element is removed from its place and replaced by another with the same formative dimensions of the same length, width, depth and the same visual and optical properties (Figure 11).

\subsection{Restoration by Casting}

Copying process of the valuable element to take advantage of its aesthetic value to create an integrated composition without missing is used in case of damaged and decomposed elements and replaces the copy element in its original place [13]. This technique is very important especially in cases where the damaged formative element covers the structural elements that must be reached and reinforcement to avoid the collapse of the building. This case, which was represented when there was a fire in dome of Abu El-Hagag in Luxor and the stucco stalactites deformed and extended the damage to the structural dome of the brick and wood and then based on the restoration programs a reduction was made of the rest of the original formations after the work of a casting on the remaining part repeated and then the back structural elements are reinforced, and complete 


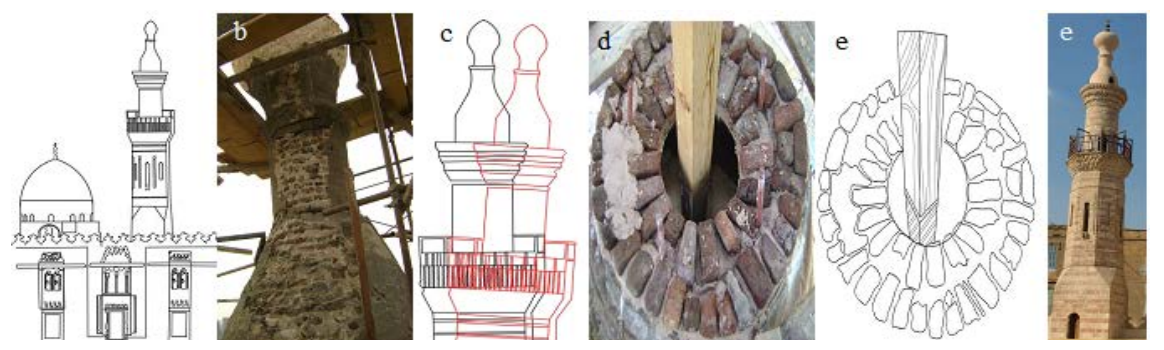

Figure 11. The process of replacing the top of minaret of the Elmas El Hajib after making sure it is not authentic, deformation and rebuilds it according to its original design.

reproduction of the dome and reconstruction of the copy in the original place (Figure 12).

\subsection{Restoration by Cleaning}

The removal of the stains is not only a means of cleaning, but a means of preserving, treating the effect or to prevent the decomposition of the effect of decay. In addition it is a means to maintain the permanence and stability of the impact material (Figure 13).

\subsection{Restoration by Reinforcement Using Iron Bonds}

The reinforcement processes are great importance, accuracy and privacy in the field of archaeological application. This is due to the fact that it deals with the structure of the surface and interior effect [14], which requires careful care to prevent the internal distortion of the structure of the archaeological material (Figure 14).

\subsection{Restoration by Show Hidden Decorations}

Restoration by show hidden decorations under new coatings is based on respect for the original material and its original design (Authenticity), and removal of additional elements, which have distorted or hide the old character of the building (Figure 15).

\section{Conclusion and Recommendation}

Architect reacts with the structural unit not only from the point of view of structural efficiency but also showing and deliver architectural language. Architecture itself is the art of forming blocks, in addition to the shape and texture of surfaces, colors, scale, construction and changing lighting. Architecture represented in the creation of contradictory and integrated elements, to produce an architectural art, which achieved creativity and express the environment and age. The aesthetic and morphological effects are unavoidable, from the complexities of the concept of restoration, and there is no philosophy of restoration that can be applied in all cases of all ages and in all places. Rather, it is necessary to select the appropriate vision and philosophy of restoration for each individual effect, which takes into consideration all the historical, archaeological and aesthetic conditions surrounding this effect, and in the case of studying the possibility of 


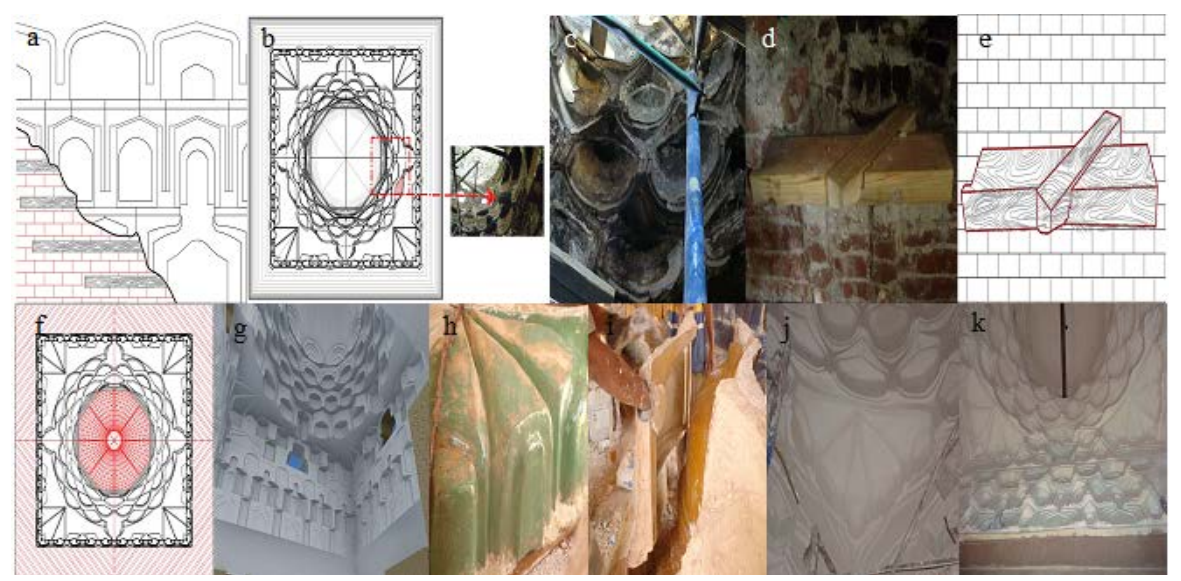

Figure 12. Steps of the casting process in the mold and reproduction of the dome of the Abu Hagag in Luxor which damaged by the fire $(a, b, c)$ diagnosis of damage and identification of architectural, structural and formative dome elements (e, f) analysis and study of the structural system ( $\mathrm{g}$ ) make a three-dimensional model of the dome after reconstruction $(h, i)$ casting process $(j, k)$ reconstruction of the simulated copy for the original.

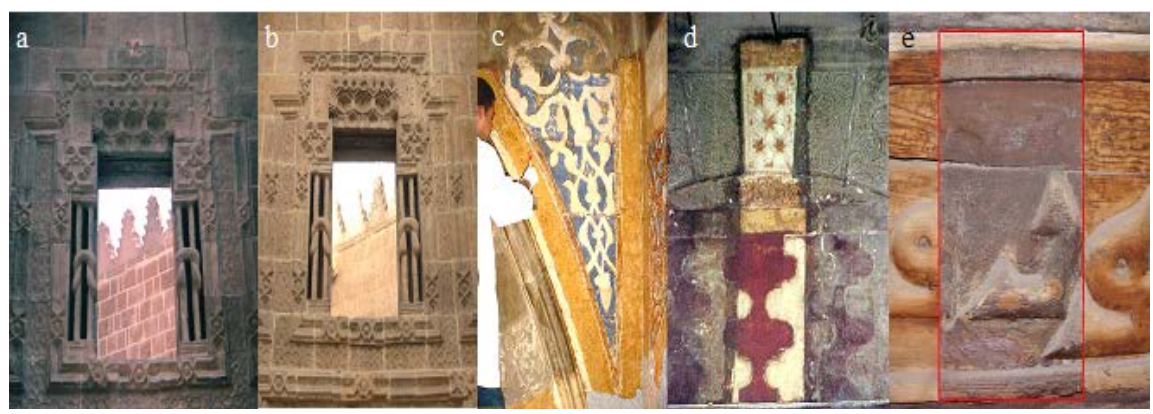

Figure 13. Different applications for the cleaning process $(a, b)$ the upper part of the entrance of Hassan Pasha Taher Complex is characterized by the hollow sculpture of columns (c, d) cleaning of the color composition elements in the Sabil of Ashraf Qaitbay in Sayda Zeinab (e) clean a wood written carving tape.

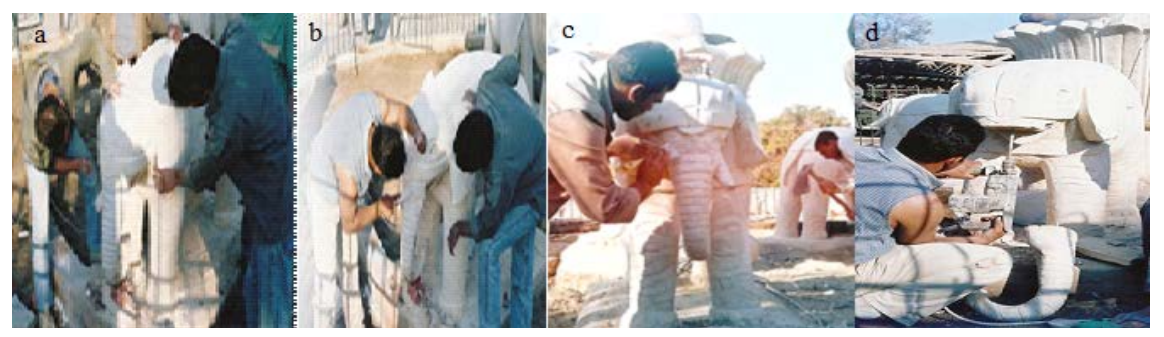

Figure 14. Stages of the process of strengthening and re-installing the separate parts of the elephants in the Japanese garden in Helwan.

applying a modern technology, the article recommend that, there should be some criteria and limitations for the application of technology. The most important safety of the technology must achieve sufficient safety factor to be applied or give sufficient warnings when a problem occurs. Compatibility and integration are with the structural system of the existing structural integrity so as not to cause structural problems. Continuity of technical efficiency over time 


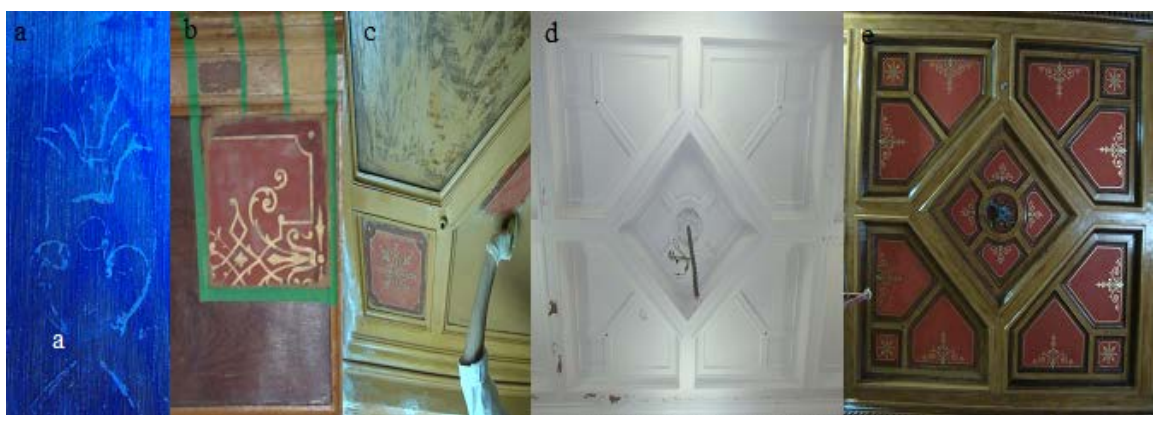

Figure 15. The show of the hidden decorative at the ceiling of one of the rooms of Sursoq Palace in Alexandria by discovering the original layers of decoration, which were hidden under new accumulated paints layers.

is under the influence of natural and non-natural factors and availability of materials. The search provided number of practical different techniques through which it is possible to remove the damage of the architectural formations of the archeological buildings and their restoration, as restoration by architectural simulation when the necessity of the horizontal or vertical extension of the building is for the purpose of developing their functions or restoration by completing the missing elements, especially as it represents a weakness in the structural composition of elements and restoration by replacing the elements that still exist but have lost their ability to carry out their essential functions, and restoration by casting and copying of the elements that must be removed for the restoration of the structural elements below and the restoration by the addition of back support of the decorative ceilings, and by restoring the structural balance of the elements that suffer from tendencies such as columns and minarets or restoration by Stitching through added elements as wood and iron, as well as the restoration by applying injection technology for internal fillings in the thickness of the walls and also the restoration by cleaning to show hidden features.

\section{Conflicts of Interest}

The author declares no conflicts of interest regarding the publication of this paper.

\section{References}

[1] Al-Alfi, M. (1998) The Philosophy of Restoration and Rehabilitation of Historical Facilities. Arab Conference for Restoration and Rehabilitation of Installations, Cairo, 1059-1066.

[2] Erder, C. (2005) Our Architectural Heritage from Consciousness to Conservation. United Nations Educational, Scientific and Cultural Organization (UNESCO 2005), 172.

[3] Sherif, M.A. (1994) Seismic Risk Appraisal for Islamic Minarets. Faculty of Engineering, Cairo University, Giza, 4.

[4] Croci, G. (1994) Damages and Restoration of Monument in Cairo. III International Symposium of the Conservation of Monuments in the Mediterranean, Basin, Venice, 27. 
[5] Mahran, F. (2007) Anwar Methodology of the Formation of Architectural Elements as Part of the Architectural Restoration Methodology in Archaeological Buildings. Faculty of Architecture, Cairo University, Giza.

[6] Abdel Tawab, N. and Mahran, N. (2015) Restoration and Preservation of Artistic Elements Applied on Islamic Architectural Facade of Shahen Agha Sebil Cairo Egypt. International Journal of Conservation Science, 6, 63-78.

[7] Abdel Tawab, N. and Mahran, N. (2013) Conservation of the Mural Stucco Ornaments of the Mausoleum of Al Amir Ulmass Al Hagib in Cairo. E-Conservation, 153-167.

[8] Brebbia, C.A. (2002) Structural Studies, Repairs, and Maintenance of Heritage Architecture, VIII. WIT Press Transactions on the Built Environment International Journal of Sustainable Development and Planning, 167.

[9] Ashurst, S. and Dime, G.F. (1998) Conservation of Building \& Decorative Stone. Read Educational \& Professional Publishing Ltd., Oxford, 10.

[10] Henriques, F. and Charolo, A. (2000) Development of Lime Mortars with Improved Resistance to Sodium Chloride Crystallization. 335-342.

[11] Bassier, C. (1977) Some Problems in the Conservation of Mosaics. No. 1, ICCROM, 69.

[12] Ellis, L.W. (2007) Stitching, the Maintenance of Brick and Stone, Masonry Structure, op. cit., 263. The Brick Industry Association, Reston.

[13] Jukka, J. (1995) Reconstruction of Ancient Remains. Conservation and Management of Archaeological Sites, 1, 69-71.

[14] (2001) Convention for Heritage Preservation. A Breif History, UNESCO Website. www.uneco.org/whe/5 hitory.com 